\title{
Impact of a Eukaryotic Translation Initiation Factor 3a Polymorphism on Susceptibility to Gastric Cancer
}

\author{
Kuijie Liu Zhendong Lei Hongliang Yao Sanlin Lei Hua Zhao \\ Department of General Surgery, The Second Xiangya Hospital, Central South University, Changsha, PR China
}

\author{
Key Words \\ Eukaryotic translation initiation factor 3a . Polymorphisms . \\ Gastric cancer
}

\begin{abstract}
Objective: To investigate single nucleotide polymorphisms in the eukaryotic translation initiation factor 3a (elF3a) gene and the risk for gastric cancer within the Chinese population. Subjects and Methods: A total of 322 patients with gastric cancer were selected as the patient group and 340 non-gastric cancer patients were selected as the control group using the case-control method. Polymerase chain reaction-sequence-specific primer technology was leveraged to genotype the rs77382849 single nucleotide polymorphism in the elF3a gene. The demographic characteristics of the study population and other exposures to risk factors were collected. Unconditional logistic regression analysis was performed to determine the association between the risk factors and gastric cancer. Results: A higher frequency of the elF3a rs77382849 GG homozygote genotype was observed in the gastric cancer patients compared with the controls (63.98 vs. $54.41 \%, \mathrm{p}<0.05)$. After adjustment of exposure risks, such as age, gender, smoking, and drinking, the rs77382849 single nucleotide polymorphism was still associated with susceptibility to gastric cancer. When the elF3a rs 77382849 GG homozygote genotype was used as the reference group, the GA genotype (GA vs. GG: OR $=0.545,95 \% \mathrm{Cl}: 0.386-0.769$,
\end{abstract}

$\mathrm{p}=0.001)$ and $\mathrm{AA}$ genotype (AA vs. GG: $\mathrm{OR}=0.245,95 \% \mathrm{Cl}$ : $0.072-0.836, p=0.025$ ) were both correlated with a significantly decreased risk for gastric cancer development. Conclusion: An association between elF3a rs77382849 polymorphism and susceptibility to gastric cancer was observed in these Chinese patients.

(c) 2016 S. Karger AG, Basel

\section{Introduction}

Gastric cancer is one of the common alimentary canal malignancies, the incidence of which ranks fourth among malignancies globally [1]. Every year, approximately 1 million new cases of gastric cancer are diagnosed [2]. A total of $15 \%$ of confirmed gastric cancer patients will survive for 5 years, while $5 \%$ will survive for 10 years [3]. As many as 500,000 people have died from gastric cancer every year worldwide; gastric cancer is the second leading cause of malignant death [4].

Due to the lack of symptoms in the early stage, gastric cancer is diagnosed at an advanced stage, and hence patient treatment is not effective [5]. Therefore, early detection and diagnosis are key to reducing the fatality rate of gastric cancer. The fact that only a small proportion of people who are exposed to relative risk factors develop gastric cancer also suggests that identifying high-risk individuals could play an essential role in medical manage- 
ment [6]. In recent years, many studies have shown that gastric cancer has been closely related to a variety of cancer genes, DNA repair genes, and gene mutations in metabolic enzymes $[7,8]$.

Eukaryotic translation initiation factors (eIFs) are a type of protein that involves the whole translation process of the protein in eukaryotic cells to ensure the formation of the mRNA-ribosome-associated complex. Currently, more than 20 eIF family members have been identified [9]. Most studies had been devoted to eIF2, eIF3, eIF4, and eIF5 [10]. eIF3, composed of at least 12 subunits labeled eIF3a to eIF3m, is the most complicated and at the same time most important in the family of eIFs. Different subunits play different roles in the tumor: they can either control or cause tumor growth [11].

eIF3a, also known as eIF3 p170, serves as the bridge during the translational process [12]. A previous study showed that eIF3a was overexpressed in gastric, breast, and esophageal cancers, indicating that eIF3a may cause tumor growth [13]. However, the specific mechanism for tumor development has not been elucidated. Dong et al. [14] reported that overexpression of eIF3a could cause upregulation of $\alpha$-tubulin and subunits of ribonucleotide reductase, while underexpression could cause downregulation of p27kip/Kipl [15], thus influencing cell proliferation, differentiation, and cycle control [11]. Therefore, eIF3a may cause the development of tumors through regulation of mRNA translation in the developing tumor as well as aberrant cell growth.

The eIF3a gene consists of 24 exons and 23 introns that are located in chromosome 10q26 [16]. Studies have shown that mutation of eIF3a is associated with susceptibility to tumor growth. Many studies have shown that single nucleotide polymorphisms are associated with tumor etiology, diagnosis, and prognosis $[17,18]$. As for the study of polymorphisms in eIF3a, most research has been focused on lung cancer, breast cancer, and prostatic cancer [ 19,20$]$. Olson et al. [21] screened 205 gene polymorphisms in 30 genes from 798 breast cancers and found that mutation of eIF3a rs10787899 A>G and rs3824830 $\mathrm{C}>\mathrm{T}$ was significantly associated with susceptibility to gastric cancer. Thus far, no study has been performed to examine the association between rs77382849 and susceptibility to gastric cancer. Exploration of the association between eIF3a gene polymorphisms and susceptibility to gastric cancer is of vital importance for discovering new markers of gastric cancer. Therefore, the objective of this study was to analyze the eIF3a rs77382849 polymorphism and explore its association with susceptibility to gastric cancer.

\section{Subjects and Methods}

\section{Selection of Study Population}

A total of 322 cases with gastric cancer and 340 controls were enrolled in this study. These gastric cancer patients were consecutively diagnosed from March 2012 to March 2014 in the oncology and general surgery departments at The Second Xiangya Hospital. The exclusion criteria were secondary or recurrent tumors, and a history of other malignant neoplasms. The controls were non-gastric cancer patients who had completed a physical check in health examination center of The Second Xiangya Hospital between March 2012 and March 2014. The exclusion criteria for controls were a history of other malignant neoplasms and any digestive disease.

The Central South University Ethics Review Committee approved the protocol. Investigations conformed to the principles outlined in the declaration of Helsinki, and written informed consent was obtained from all the subjects.

A self-developed questionnaire was used to collect data that included recalling the situation of exposure before appearance of continuous respiratory symptoms. The questionnaire included 9 closed-ended questions about age, gender, occupation, marital status, educational level, smoking and drinking status, and whether the subject takes part in physical exercise or not. Five milliliters of venous whole blood were collected in an EDTA anticoagulant tube from participants and stored at $4^{\circ} \mathrm{C}$ before use. A blood DNA small kit was used to extract peripheral white blood cell genomes (Shanghai Sangon Biotech Co., Ltd.).

\section{Genotyping}

The polymerase chain reaction (PCR)-sequence specific primer technology was leveraged to genotype the rs77382849 in the eIF3a gene. The site sequence of rs77382849 in the eIf3a gene was identified in GenBank, and appropriate primers (sense primer 5'-AAAAGGCAGCGTAAAGAAGACTGC-3', anti-sense primer $5^{\prime}$-TGGCAGACGATGTAACAACTT- $3^{\prime}$ ) were designed with Primer Premier 5.0, the specificity of which was verified using Blast (a software of NCBI). Primers were produced by Shanghai Sangon Biotech Co, Ltd. The PCR reaction was a total of $20 \mu \mathrm{l}$, which included a $10-\mu \mathrm{l}$ mixture of $0.8 \mu \mathrm{l}$ DNA ( $10 \mathrm{ug} / \mathrm{dl}), 0.4 \mu \mathrm{l}$ of upstream primers, $0.4 \mu \mathrm{l}$ of downstream primers, and $8.4 \mu \mathrm{l}$ of $\mathrm{ddH}_{2} \mathrm{O}$. The reaction condition was $94^{\circ} \mathrm{C}, 3 \mathrm{~min}$ for 40 cycles $\left(94^{\circ} \mathrm{C}\right.$ for $30 \mathrm{~s}$, $58^{\circ} \mathrm{C}$ for $30 \mathrm{~s}$, and $72^{\circ} \mathrm{C}$ for $60 \mathrm{~s}$ ), and $72^{\circ} \mathrm{C}$ extension for $5 \mathrm{~min}$.

The enzyme digestion reaction was a total of $10 \mu$ l, including $2 \mu \mathrm{l}$ of PCR product, $1 \mu \mathrm{l}$ of $10 \times$ buffer, $0.5 \mu$ of restriction endonuclease PstI, and $6.5 \mu \mathrm{l}$ of $\mathrm{ddH}_{2} \mathrm{O}$. The Pst I enzyme digests wild-type EIF3a rs77382849 containing a $\mathrm{G}$ allele by recognizing the ' $\mathrm{CTGCA} \wedge \mathrm{G}^{\prime}$ sequence. A mutant-type eIF3a rs77382849 containing an A allele was left. The reaction was kept at $37^{\circ} \mathrm{C}$ overnight. Five microliters of the enzyme-digested product were applied to a $3 \%$ agarose gel (containing $0.5 \mu \mathrm{g} / \mathrm{ml}$ of ethidium bromide). The electrolytic buffer solution was a $0.5 \times$ Tris Buffer EDTA solution, and the voltage for the sample migration was set at $120 \mathrm{~V}$. Electrophoresis was performed for $40 \mathrm{~min}$. A gel imaging processing system was used to observe the electrophoresis results, determine the genotype, and take photos.

\section{Statistical Analysis}

EpiData 3.0 was used to input data, and SAS 9.2 was used to analyze the data. The $\chi^{2}$ test was conducted for the comparison of grouped data. Logistic regression was used for multivariate analysis. All hypothesis tests were two tailed with a type 1 error rate fixed at $5 \%$. 
Table 1. Comparison of the basic information between the patient and control groups

\begin{tabular}{|c|c|c|c|c|c|c|}
\hline \multirow[t]{2}{*}{ Variables } & \multicolumn{2}{|c|}{ Case } & \multicolumn{2}{|c|}{ Control } & \multirow[t]{2}{*}{$\chi^{2}$} & \multirow[t]{2}{*}{$\mathrm{p}$} \\
\hline & $\mathrm{n}$ & $\%$ & $\mathrm{n}$ & $\%$ & & \\
\hline \multicolumn{7}{|l|}{ Gender } \\
\hline Female & 214 & 66.46 & 228 & 67.06 & 0.027 & 0.870 \\
\hline Male & 108 & 33.54 & 112 & 32.94 & & \\
\hline \multicolumn{7}{|l|}{ Age, years } \\
\hline $47-59$ & 51 & 15.84 & 48 & 14.12 & 2.443 & 0.486 \\
\hline $60-64$ & 124 & 38.51 & 145 & 42.65 & & \\
\hline $65-69$ & 99 & 30.75 & 90 & 26.47 & & \\
\hline $70-81$ & 48 & 14.91 & 57 & 16.76 & & \\
\hline \multicolumn{7}{|l|}{ Occupation } \\
\hline Farmer & 152 & 47.2 & 167 & 49.12 & 0.242 & 0.623 \\
\hline Not a farmer & 170 & 52.8 & 173 & 50.88 & & \\
\hline \multicolumn{7}{|l|}{ Education } \\
\hline Primary school or less & 125 & 38.82 & 140 & 41.18 & 1.117 & 0.572 \\
\hline Junior middle school & 105 & 32.61 & 98 & 28.82 & & \\
\hline Senior high school or more & 92 & 28.57 & 102 & 30.00 & & \\
\hline \multicolumn{7}{|l|}{ Marital status } \\
\hline Married & 224 & 69.57 & 240 & 70.59 & 0.083 & 0.774 \\
\hline Other & 98 & 30.43 & 100 & 29.41 & & \\
\hline \multicolumn{7}{|l|}{ Smoking } \\
\hline No & 127 & 39.44 & 195 & 57.35 & 21.239 & $<0.001$ \\
\hline Yes & 195 & 60.56 & 145 & 42.65 & & \\
\hline \multicolumn{7}{|l|}{ Drinking } \\
\hline No & 267 & 82.92 & 303 & 89.12 & 5.310 & 0.021 \\
\hline Yes & 55 & 17.08 & 37 & 10.88 & & \\
\hline \multicolumn{7}{|l|}{ Tea-drinking } \\
\hline No & 287 & 89.13 & 260 & 76.47 & 18.466 & $<0.001$ \\
\hline Yes & 35 & 10.87 & 80 & 23.53 & & \\
\hline \multicolumn{7}{|l|}{ Physical exercise } \\
\hline No & 250 & 77.64 & 236 & 69.41 & 5.736 & 0.017 \\
\hline Yes & 72 & 22.36 & 104 & 30.59 & & \\
\hline \multicolumn{7}{|l|}{ rs77382849 } \\
\hline GG & 206 & 63.98 & 185 & 54.41 & 7.911 & 0.019 \\
\hline GA & 112 & 34.78 & 144 & 42.35 & & \\
\hline AA & 4 & 1.24 & 11 & 3.24 & & \\
\hline \multicolumn{7}{|l|}{ Allele } \\
\hline G & 524 & 81.37 & 514 & 75.59 & 6.521 & 0.011 \\
\hline A & 120 & 18.63 & 166 & 24.41 & & \\
\hline
\end{tabular}

\section{Results}

Basic information on the patient and control group is described in table 1 . No statistical significance was noted between the groups concerning age, gender, occupation, education, marriage, etc. $(p>0.05)$. The $\chi^{2}$ test showed that the patients were more likely to smoke and drink than the control group $(\mathrm{p}<0.05)$. Statistical significance was observed between the two groups for tea consumption and physical exercise $(\mathrm{p}<0.05)$. Distribution frequency of rs77382849 GG, GA, and AA in the patient group was
$63.98,34.78$, and $1.24 \%$, respectively, and the corresponding distribution frequency in the control group was 54.41, 42.35 , and $3.24 \%$. The genotype distribution frequencies of the two groups reached statistical significance $(\mathrm{p}<$ 0.05 ). The rs 77382849 GG genes were more prevalent in the gastric cancer group than the control group.

Logistic regression analysis revealed that rs77382849 genes were associated with the susceptibility for gastric cancer. Among the factors, smoking $(\mathrm{OR}=2.672,95 \% \mathrm{CI}$ : $1.856-3.848)$ and drinking $(\mathrm{OR}=2.897,95 \% \mathrm{CI}: 1.756-$ 4.781) were risk factors for gastric cancer, whereas tea 
Table 2. Logistic regression analysis of multifactor for susceptibility to gastric cancer

\begin{tabular}{|c|c|c|c|c|c|c|c|}
\hline \multirow[t]{2}{*}{ Variables } & \multirow[t]{2}{*}{ B } & \multirow[t]{2}{*}{ SE } & \multirow[t]{2}{*}{ Wals } & \multirow[t]{2}{*}{$\mathrm{p}$} & \multirow[t]{2}{*}{ OR } & \multicolumn{2}{|l|}{$95 \% \mathrm{CI}$} \\
\hline & & & & & & lower & upper \\
\hline rs77382849 GG & & & 150.182 & 0.001 & & & \\
\hline rs77382849 GA & -0.607 & 0.176 & 110.927 & 0.001 & 0.545 & 0.386 & 0.769 \\
\hline rs77382849 AA & -10.408 & 0.627 & 50.044 & 0.025 & 0.245 & 0.072 & 0.836 \\
\hline Gender & -0.110 & 0.180 & 0.374 & 0.541 & 0.896 & 0.629 & 10.275 \\
\hline Smoking & 0.983 & 0.186 & 270.928 & $<0.001$ & 20.672 & 10.856 & 30.848 \\
\hline Age & 0.015 & 0.106 & 0.020 & 0.888 & 10.015 & 0.824 & 10.250 \\
\hline Marriage & -0.071 & 0.189 & 0.140 & 0.708 & 0.932 & 0.643 & 10.350 \\
\hline Education & -0.055 & 0.128 & 0.186 & 0.666 & 0.946 & 0.737 & 10.215 \\
\hline Tea drinking & -0.825 & 0.237 & 120.086 & 0.001 & 0.438 & 0.275 & 0.698 \\
\hline Drinking & 10.064 & 0.256 & 170.335 & $<0.001$ & 20.897 & 10.756 & 40.781 \\
\hline Physical exercises & -0.387 & 0.191 & 40.114 & 0.043 & 0.679 & 0.467 & 0.987 \\
\hline Occupation & 0.040 & 0.192 & 0.044 & 0.834 & 10.041 & 0.715 & 10.517 \\
\hline Constant & -0.180 & 0.449 & 0.160 & 0.689 & 0.836 & & \\
\hline
\end{tabular}

drinking $(\mathrm{OR}=0.438,95 \% \mathrm{CI}: 0.275-0.698)$ and physical exercise (OR $=0.679,95 \%$ CI: $0.467-0.987)$ were protective factors. After adjustment for factors such as gender, age, and smoking, rs77382849 remained associated with susceptibility to gastric cancer. Among them, rs77382849 GG genes were risk factors for gastric cancer development $(\mathrm{OR}=0.545)$, while rs77382849 GA genes and rs77382849 AA genes were protective factors $(\mathrm{OR}=$ 0.245) (table 2).

\section{Discussion}

In this study, the frequency of mutant rs77382849 G>A of eIF3a gene in the gastric cancer group was different from that of the healthy control group; this difference in the polymorphism of the eIF3a gene indicated that the presence of the $G$ allele was associated with susceptibility to gastric cancer.

The finding that an association exists between eIF3a rs77382849 gene and susceptibility to gastric cancer was observed in ovarian cancer [22], but a TT genotype was not observed, which could be due to small sample size.

Considering the distribution of genotypes in gastric cancer group and healthy control group, the GG genotype was more frequent in gastric cancer patients than in controls, probably because gastric cancer might be influenced by the GG polymorphism of eIF3a rs77382849. Hence, carrying the $T$ allele could have a protective effect against gastric cancer. Recent epidemiological and genetic association studies have shown that gastric cancer is asso- ciated with polymorphisms in oncogenes [23], metabolizing enzyme genes [8], DNA repair genes [24], and immune-related genes [25]. However, the biological mechanism of how genetic polymorphism in eIF3a rs77382849 contributes to gastric cancer is not completely clear. IF3a has been reported to have a variety of biological functions. At the initial stage of translation, eIF3a together with various types of translation initiation factors form the 40S ribosomal subunit that regulates RNA translation [10]. Additionally, eIF3a is able to up- or downregulate the synthesis of p27kipl, $\alpha$-tubulin, and RRM2 protein to regulate cell cycle and proliferation [26]. Dong et al. [14] reported that suppression of endogenous eIF3a expression could reverse the deterioration of cancer cells, and Zhang et al. [27] observed that cells transformed by overexpression of eIF3a lead to a number of oncogenic properties such as increased rates of proliferation and clonogenicity, anchorage-independent growth, loss of contact inhibition, and greater metabolic activity, and thereby may play an important role in neoplasia.

Gene-environment or gene-lifestyle interactions could lead to the varying genetic effects observed in different studies $[28,29]$. Evidence has indicated that environmental factors such as cigarette smoking and diet might play an important role in gastric carcinogenesis [30]. After adjustment for other confounding factors, the present study found that gastric cancer was still associated with polymorphisms of eIF3a rs7738284.

To our knowledge, this is the first report in the Chinese population regarding the association between eIF3a rs77382849 polymorphism and gastric cancer. However, 
we are aware that our findings still need to be validated by additional population-based studies in different ethnic groups prospectively. Further studies are necessary to expand the sample size and to clarify the pathophysiology mechanism of eIF3a rs77382849 mutation on gastric cancer development.

\section{Conclusion}

In this study, polymorphism in eIF3a rs77382849 was associated with susceptibility of gastric cancer. This finding could be of vital importance for the study of the pathogenesis of gastric cancer and of fundamental significance for identifying the population at risk that could lead to taking proper measures to prevent the development of gastric cancer in this population. Additionally, it is of significance for the detection and screening of molecular markers in cancer. However, since the specific mechanism causing cancer is still unclear, further research and a large number of samples are still needed to confirm our findings.

\section{Disclosure Statement}

This study was supported by the grants from the National Nature Science Foundation of China (No. 81402536) and the Science and Technology Plan Fund in Hunan Province, PR China (2014WK2016, 2013FJ6053).

\section{References}

1 Malinowska M, Nasierowska-Guttmejer A: Epidemiology and pathogenesis of gastric cancer (in Polish). Pol J Pathol 2013;64:s17s26.

-2 Karimi P, Islami F, Anandasabapathy S, et al: Gastric cancer: descriptive epidemiology, risk factors, screening, and prevention. Cancer Epidemiol Biomarkers Prev 2014;23:700-713.

3 Fock KM: Review article: the epidemiology and prevention of gastric cancer. Aliment Pharmacol Ther 2014;40:250-260.

4 Patru CL, Surlin V, Georgescu I, et al: Current issues in gastric cancer epidemiology. Rev Med Chir Soc Med Nat Iasi 2013;117:199-204.

5 de Mestier L, Lardiere-Deguelte S, Volet J, et al: Recent insights in the therapeutic management of patients with gastric cancer. Dig Liver Dis 2016, Epub ahead of print.

6 Prucka SK, McIlvried DE, Korf BR: Cancer risk assessment and the genetic counseling process: using hereditary breast and ovarian cancer as an example. Med Princ Pract 2008; 17:173-189.

-7 Cui J, Yin Y, Ma Q, et al: Comprehensive characterization of the genomic alterations in human gastric cancer. Int J Cancer 2015;137:8695.

8 Devulapalli K, Bhayal AC, Porike SK, et al: Role of interstitial collagenase gene promoter polymorphism in the etiology of gastric cancer. Saudi J Gastroenterol 2014;20:309-314.

-9 Saletta F, Suryo Rahmanto Y, Richardson DR: The translational regulator eIF3a: the tricky eIF3 subunit! Biochim Biophys Acta 2010 1806:275-286.

10 Dong Z, Zhang JT: Initiation factor eIF3 and regulation of mRNA translation, cell growth, and cancer. Crit Rev Oncol Hematol 2006;59: 169-180.

11 Yin JY, Dong Z, Liu ZQ, et al: Translational control gone awry: a new mechanism of tumorigenesis and novel targets of cancer treatments. Biosci Rep 2011;31:1-15.
12 Liu Z, Dong Z, Yang Z, et al: Role of eIF3a (eIF3 p170) in intestinal cell differentiation and its association with early development. Differentiation 2007;75:652-661.

13 Shen J, Yin JY, Li XP, et al: The prognostic value of altered eif3a and its association with p27 in non-small cell lung cancers. PLoS One 2014;9:e96008.

14 Dong Z, Liu LH, Han B, et al: Role of eIF3 p170 in controlling synthesis of ribonucleotide reductase M2 and cell growth. Oncogene 2004; 23:3790-3801.

15 Borriello A, Bencivenga D, Criscuolo M, et al: Targeting p27Kip1 protein: its relevance in the therapy of human cancer. Expert Opin Ther Targets 2011;15:677-693.

16 Spilka R, Ernst C, Mehta AK, et al: Eukaryotic translation initiation factors in cancer development and progression. Cancer Lett 2013; 340:9-21.

17 Yuan P, Liu D, Deng M, et al: Identification of differently expressed genes with specific SNP loci for breast cancer by the integration of SNP and gene expression profiling analyses. Pathol Oncol Res 2015;21:469-475.

18 Huang CJ, Lian SL, Hou MF, et al: SNP 1772 $\mathrm{C}>\mathrm{T}$ of HIF-1a gene associates with breast cancer risk in a Taiwanese population. Cancer Cell Int 2014;14:87.

19 Spilka R, Ernst C, Bergler H, et al: eIF3a is over-expressed in urinary bladder cancer and influences its phenotype independent of translation initiation. Cell Oncol (Dordr) 2014;37:253-267.

20 Chen G, Burger MM: P150 overexpression in gastric carcinoma: the association with p53, apoptosis and cell proliferation. Int $J$ Cancer 2004;112:393-398.
21 Olson JE, Wang X, Goode EL, et al: Variation in genes required for normal mitosis and risk of breast cancer. Breast Cancer Res Treat 2010; 119:423-430.

22 Zhang C, Zhang S, Liu Y, et al: eIF3a gene polymorphism and chemo-sensitivity to platinum-based drugs in ovarian cancer (in Chinese). Zhong Nan Da Xue Xue Bao Yi Xue Ban 2015;40:617-622.

23 Kurashige J, Mima K, Sawada G, et al: Epigenetic modulation and repression of miR-200b by cancer-associated fibroblasts contribute to cancer invasion and peritoneal dissemination in gastric cancer. Carcinogenesis 2015;36: 133-141.

24 Liu JW, He CY, Sun LP, et al: The DNA repair gene ERCC6 rs1917799 polymorphism is associated with gastric cancer risk in Chinese. Asian Pac J Cancer Prev 2013;14:6103-6108.

25 Qiu B, Zou HY, Yang YH, et al: Interleukin1B-31 gene polymorphism in Hakka gastric cancer patients in Guangdong, China. Genet Mol Res 2014;13:5873-5879.

26 Yin JY, Shen J, Dong ZZ, et al: Effect of eIF3a on response of lung cancer patients to platinum-based chemotherapy by regulating DNA repair. Clin Cancer Res 2011;17:4600-4609.

27 Zhang L, Pan X, Hershey JW: Individual overexpression of five subunits of human translation initiation factor eIF3 promotes malignant transformation of immortal fibroblast cells. J Biol Chem 2007:282:5790-5800.

28 Zhang $\mathrm{P}$, Lewinger JP, Conti $\mathrm{D}$, et al: Detecting gene-environment interactions for a quantitative trait in a genome-wide association study. Genet Epidemiol 2016;40:394-403.

29 Kurbasic A, Poveda A, Chen Y, et al: Genelifestyle interactions in complex diseases: design and description of the GLACIER and VIKING studies. Curr Nutr Rep 2014;3:400-411.

-30 Ferrari F, Reis MA: Study of risk factors for gastric cancer by populational databases analysis. World J Gastroenterol 2013;19:9383-9391. 